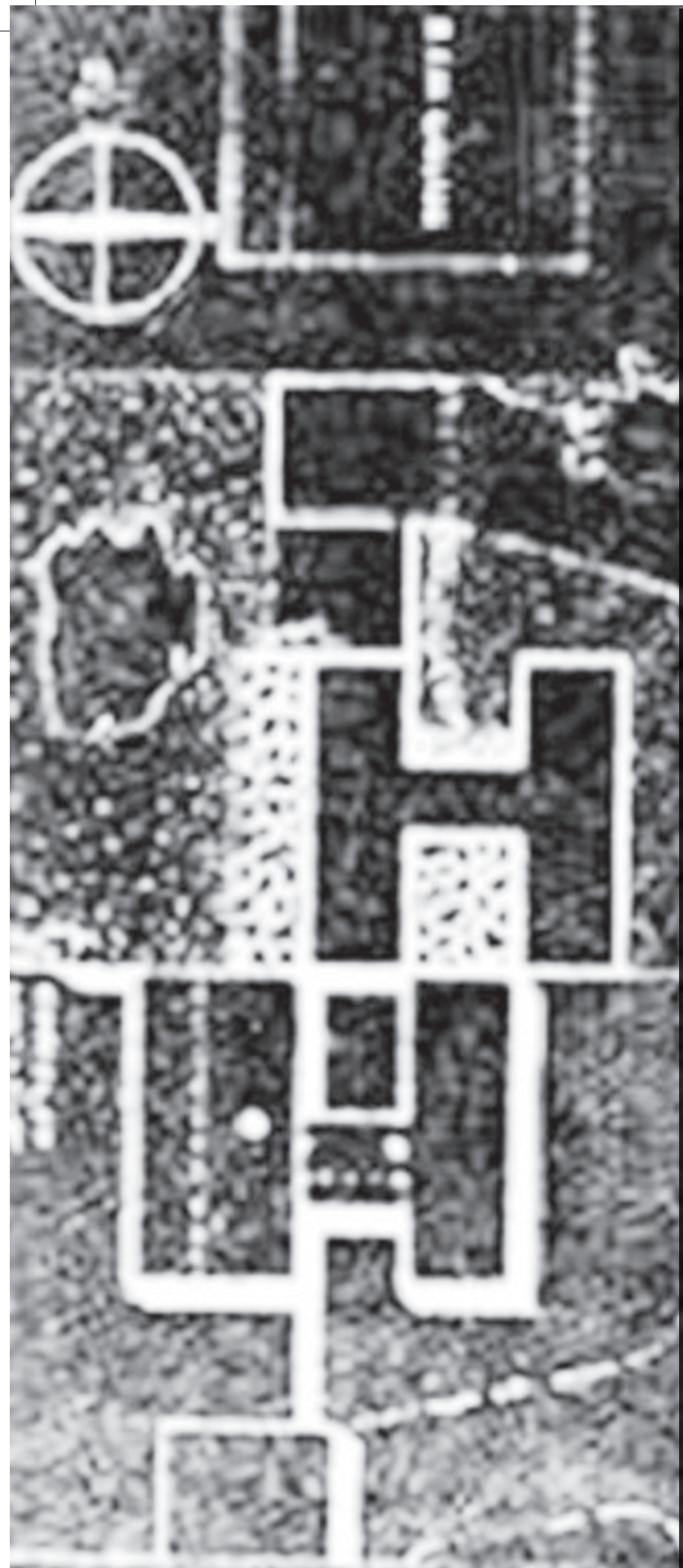

1. Este trabalho se apoia nos registros gráficos e desenhos analíticos elaborados sobre as casas Francisco Xavier e Múcio Souto, dentro dos marcos do Laboratório de Pesquisa Projeto e Memória (LPPM/PPGAU/UFPB), por duas equipes de estudantes: Lívia Sarmento de Sá e Raissa Cunha Rodrigues, e Fillipe Albuquerque Miranda e Davi Pereira Lucena.

2. Doutor em Teoria e História da Arquitetura e da Cidade pela ETSAB-UPC, professor adjunto do Departamento de Arquitetura e do Programa de Pós-Graduação da UFPB, editor do Vitruvius Espanha e arquiteto graduado pelo Centro Universitário Moura Lacerda.

3. Doutora História da Arquitetura e Historia Urbana pela ETSAB-UPC, professora associada do Departamento de Arquitetura e do Programa de Pós-graduação da UFPB, colaboradora do PPGAU/UFRN e arquiteta graduada pela UnB.

4. Mestra em Engenharia Urbana pela UFPB, professora assistente do Departamento de Arquitetura, vice-coordenadora do CAU/UFPB, arquiteta graduada pela UFPB. 


\title{
CASAS DE MARIO DI LASCIO NOS ANOS 1970: RAMPAS, MEIO NÍVEIS E DIVISÃO EM DOIS NÚCLEOS ${ }^{1}$
}

\author{
MARIO DI LASCIO HOUSES INTHE 1970S: RAMPS, HALF LEVELS \\ AND BINUCLEAR DIVISION
}

\author{
Marcio Cotrim ${ }^{2}$ \\ Nelci Tinem ${ }^{3}$ \\ Wylnna C. L. Vidal ${ }^{4}$
}

\section{Resumo}

As casas divididas em dois núcleos interligados tiveram um papel importante para a cultura arquitetônica do século XX. Permitiam uma fácil setorização das atividades da casa e ainda dissimulavam a tripartição oitocentista do programa em íntimo, social e serviços, tão questionada pelos arquitetos modernos, mas poucas vezes realmente abandonada. A organização binuclear do programa doméstico é uma estratégia presente na obra de importantes arquitetos brasileiros, como Oswaldo Bratke e Vilanova Artigas. No caso de João Pessoa-PB, a casa unifamiliar foi um meio fundamental de difusão da arquitetura moderna. Assim, considerando o aspecto particular de casas binucleares, este artigo trata de identificar, com base na leitura de duas casas projetadas pelo arquiteto paraibano Mario Di Lascio e construídas na segunda metade da década de 1970, na orla marítima de João Pessoa, uma possível fase de transição entre uma produção moderna e contemporânea em João Pessoa.

Palavras-chave: arquitetura moderna; casas binucleares; João Pessoa.

\begin{abstract}
The houses organized into two interconnected cores played an important role in the architectural culture of the twentieth century. They allowed an easy compartmentalization of the activities of home and still disguised the tripartition organization of the program of nineteenth century into intimate, social and services, and although questioned by modern architects, but rarely actually abandoned. The organization of the binuclear home program is a project strategy present in work of important brazilian architects like Oswaldo Bratke and Vilanova Artigas. In the particular case of João Pessoa-PB, the single-family home worked as an important means of dissemination of modern architecture, then, considering the particular aspect of binuclear homes, this article intents to identify, from the reading of two houses designed by architect Mario Di Lascio and built in the second half of 1970 on the seafront of João Pessoa, a possible transition phase from a modern and contemporary production in João Pessoa.
\end{abstract}

Keywords: modern architecture; binuclear houses; João Pessoa. Casas binucleares ao longo do século XX 
As casas divididas em dois núcleos interligados tiveram um papel importante para a cultura arquitetônica do século XX. Permitiam uma fácil setorização das atividades da casa e ainda dissimulavam a tripartição oitocentista do programa (íntimo, social e serviços), muitas vezes questionada pelos arquitetos modernos, mas poucas vezes realmente abandonada. Além disso, geravam quase que automaticamente pátios, outra espacialidade perseguida por alguns arquitetos no afã de reconectar sua arquitetura com a tradição doméstica de determinadas culturas como, por exemplo, a mediterrânea. Provavelmente, entre os arquitetos do século passado, aquele que mais utilizou o sistema binuclear como solução para o programa doméstico foi o húngaro Marcel Breuer (1902-1981), que, formado na Bauhaus, mudou-se para os Estados Unidos em 1937, atendendo ao convite de Walter Gropius para dar aulas em Harvard. Ao longo dos cerca de 40 anos em que viveu na América do Norte, Marcel Breuer construiu 58 casas fundamentais na definição dos parâmetros do movimento moderno nesse país, resultado de sua constante busca em identificar os requisitos da vida familiar da sociedade norte-americana no período posterior à Segunda Guerra (BREU$E R, 2001)$.

As casas projetadas em dois núcleos por Marcel Breuer eram quase sempre vinculadas aos grandes terrenos dos luxuosos bairros nos arredores das cidades norte-americanas, onde o arquiteto podia, sem grandes restrições, mover os núcleos livremente no terreno, não se restringindo assim à configuração da planta em "H". Um exemplo potente é a casa Geller I (1944-1946) em Long Island, Nova lorque. Nesse caso em particular, o acesso se dá pelo elemento que interliga os dois núcleos, separando-os segundo os períodos nos quais ocorrem as principais atividades: os ambientes de uso predominantemente diurno, como salas de estar, jantar e cozinha; e os de uso noturno, como os quartos. $\mathrm{Na}$ Geller I, provavelmente devido às dimensões do lote, Marcel Breuer optou por separar as zonas de garagem e serviços em um terceiro núcleo, isolado dos outros, mas próximo da cozinha.

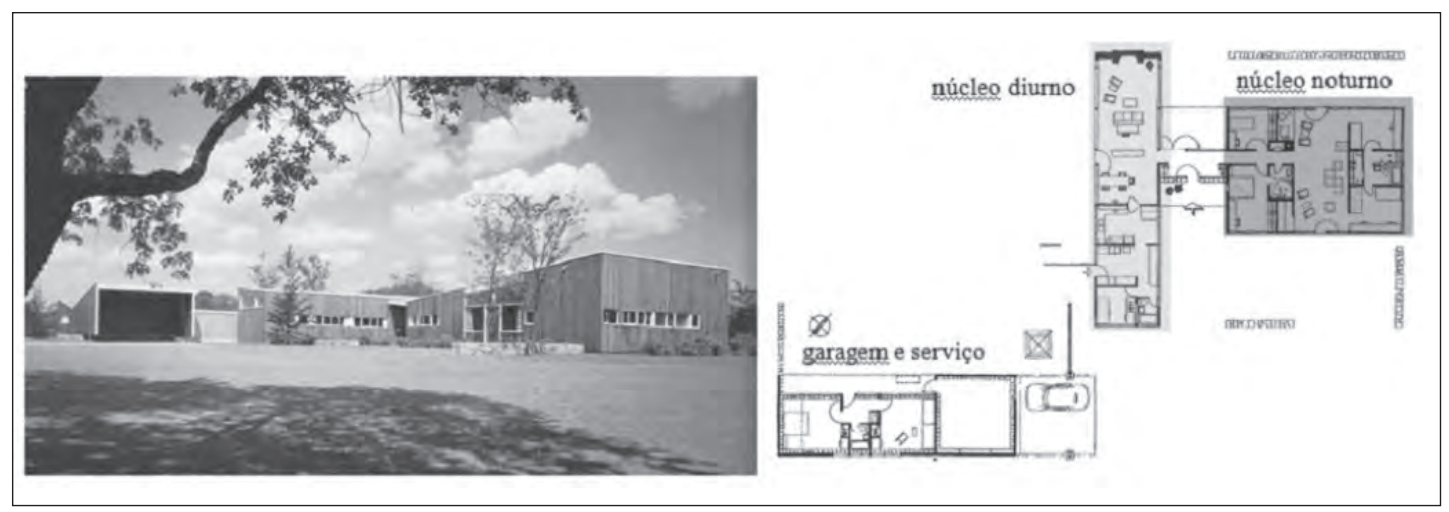

Não apenas essa, mas quase todas as outras casas construídas pelo arquiteto nos Estados Unidos eram térreas, atitude decorrente talvez do deslumbre de um europeu diante da vastidão da paisagem "americana", mas certamente uma estratégia projetual que fez das áreas externas intersticiais o prolongamento dos interiores. Essa decisão fica evidente pelo uso de muros baixos de pedras delimitando as áreas externas.
Figura 1 - Casa Geller I. Fonte: Cobbers (2009, p. 44-45).

Cadernos de Arquitetura e Urbanismo, v.18, n.22, $1^{0}$ sem. 2011 
No entanto, ao contrário das casas que consagraram o arquiteto húngaro, a primeira casa binuclear projetada por ele para o concurso organizado pela revista A\&A, em 1943, Designs for post-war living, não contava com um terreno generoso, em que os limites não condicionavam o projeto. Ao contrário, era um terreno padrão, cuja solução em dois núcleos "nasceu" atrelada ao lote vizinho, geminada, como tipo inequivocamente urbano, ou pelo menos suburbano.

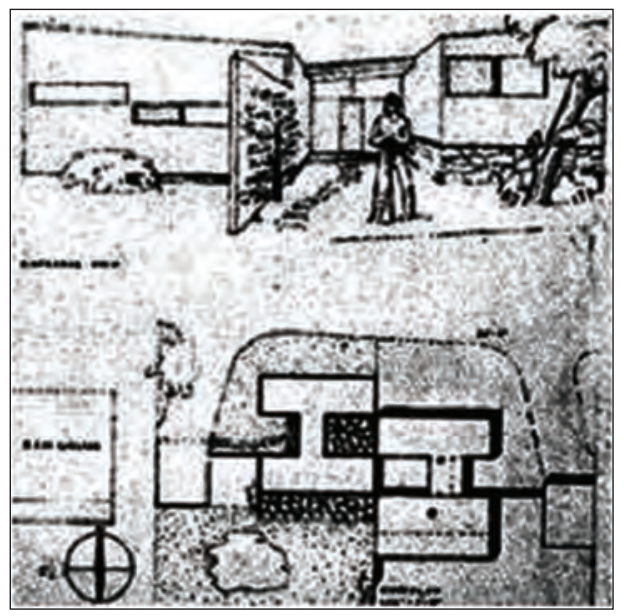

No Brasil, o esquema binuclear inspirado em Marcel Breuer (casas térreas, onde o programa era dividido em zonas de atividades noturnas e diurnas) teve eco, quase exclusivamente, por meio do arquiteto paulistano Oswaldo Bratke. ${ }^{5} \mathrm{O}$ exemplo mais claro certamente é a casa Paulo Nogueira Neto (1958-1960), construída em um dos mais luxuosos bairros-jardins da capital paulista, o Jardim América. Assim como a casa Geller I, a casa Nogueira Neto divide-se em dois núcleos interligados pelo hall de acesso e um terceiro, mais isolado, mas próximo à cozinha, que abriga os automóveis e os outros serviços da casa.
Figura 2 • Casa " $\mathrm{H}$ ", Designs for postwar living, Marcel Breuer, 1943. Fonte: Art and Architecture (apud COTRIM, 2005, p. 44).
5. A casa-ateliê de Oswaldo Bratke, à Rua Avanhandava, em outubro de 1948, foi a primeira obra latino-americana a ser publicada na revista americana Arts \& Architecture. Em 1951, com sua casa-ateliê no Morumbi, Oswaldo Bratke recebeu uma menção especial na Exposição Internacional de Arquitetura

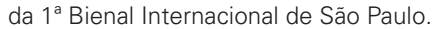

Figura 3 - Casa Paulo Nogueira Neto (1958-60) - Planta binuclear segundo conceito desenvolvido por Marcel Breuer. Fonte: SEGAWA; DOURADO (1997, p. 145).

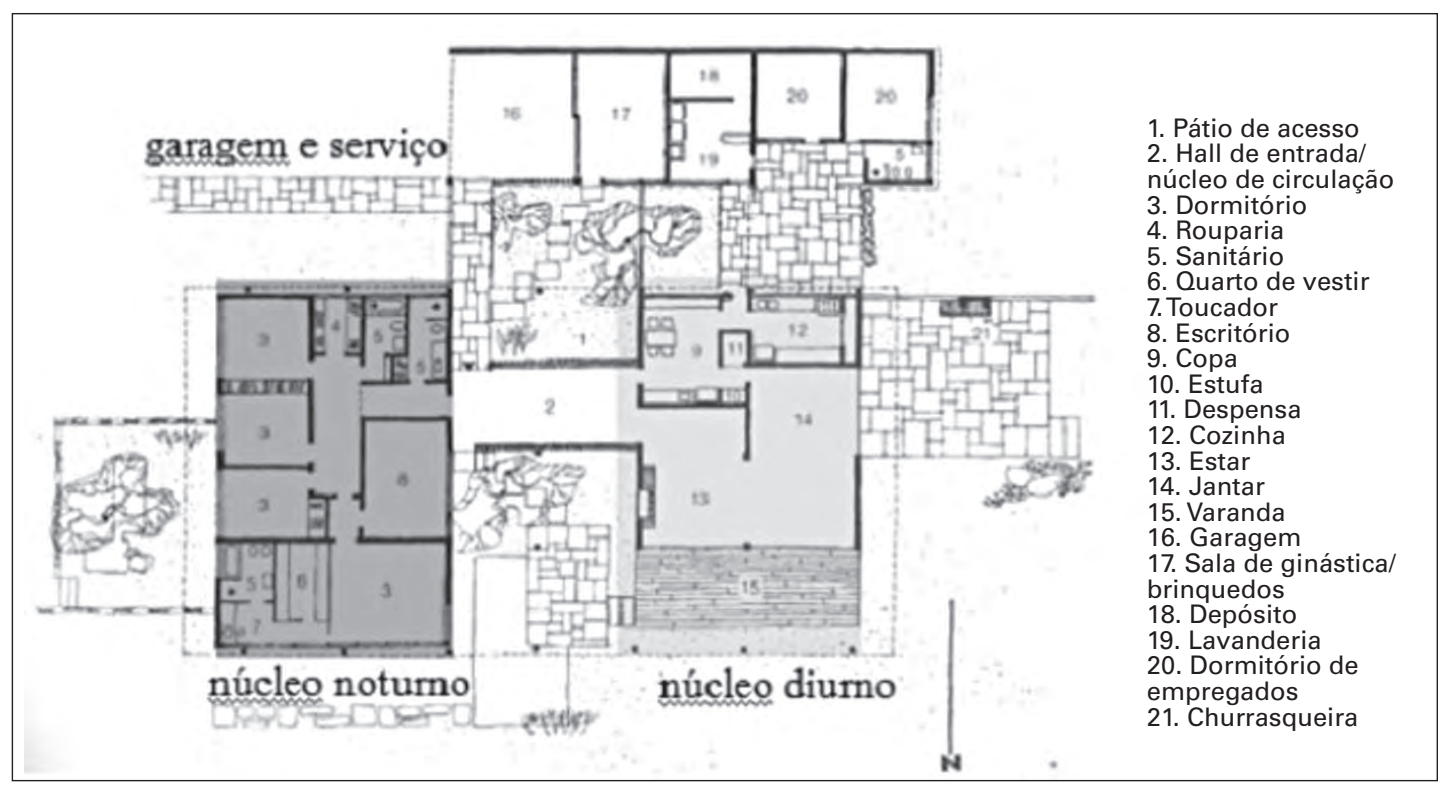




\section{Rampas, níveis intermediários e pátios residuais}

Se o esquema de planta " $\mathrm{H}$ ", tal qual Marcel Breuer desenvolveu, teve pouca aceitação no meio arquitetônico brasileiro, outras variações (plantas em "I", "L" e "U") reinaram entre arquitetos brasileiros desde a década de 1940 até, ao menos, a de 1970. Nesses casos, o uso de rampas em meios-níveis tornou-se um "hit" da década de 1950, permanecendo assim durante as duas décadas seguintes. Provavelmente a gênese dessa estratégia esteja na casa Errazuris (1930), projetada por Le Corbusier. Nessa casa, o uso de rampa em dois níveis parece levar Le Corbusier ao uso do telhado borboleta, alcançando gradativamente, com a rampa, a altura desejada e atrelando a uma planta retangular (em "I"), duas das características mais marcantes da arquitetura moderna brasileira: a rampa e o telhado borboleta.

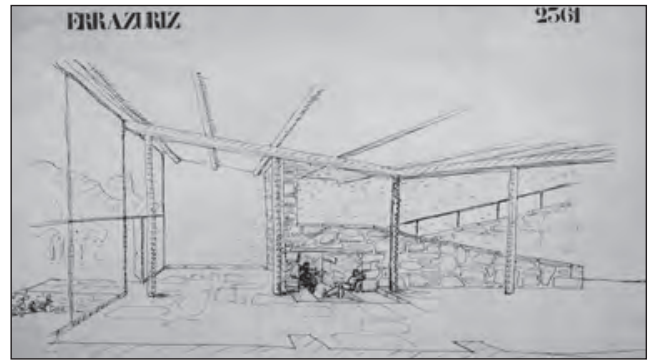

Oscar Niemeyer, aproveitando a enxurrada de encomendas no Estado de Minas Gerais, rapidamente se apropriou de ambas as operações. Na Pampulha, utilizou, separadamente, as rampas em meios-níveis no cassino e a cobertura borboleta no late Clube. No entanto, na mesma época, voltou a uni-las em duas casas em Belo Horizonte: a de Pedro Aleixo, já demolida, e o primeiro projeto da casa para Juscelino Kubitschek (não construído), ambas com plantas com formato em "L" Na última, Oscar Niemeyer incluiu ainda inclinações nas paredes laterais, definindo um volume trapezoidal, outro " hit".

Essas estratégias (as rampas em meios-níveis, a cobertura borboleta e o volume trapezoidal utilizado em plantas em "L") foram incorporadas rapidamente ao repertório de inúmeros arquitetos brasileiros, pelos quatro cantos do País. O uso de tais estratégias, quase sempre associadas ao uso do brise-soleil, passou a caracterizar a produção moderna brasileira, não raro, vinculada à ideia de uma escola carioca.

A solução que reúne a cobertura borboleta e as rampas em níveis intermediários em uma planta em "L" definida por Oscar Niemeyer na casa JK, deriva facilmente para uma solução próxima à binuclear, como é o caso da Casa D’Estefani (1952), de Vilanova Artigas, em que sua condição urbana prefigura uma repetição da primeira casa " $\mathrm{H}$ " de Breuer, porém com um único pátio.

Processos coetâneos e semelhantes ocorreram na região Nordeste do Brasil, em projetos de arquitetos que, tendo se formado no Rio de Janeiro, regressaram ou foram para a região. Um exemplo bastante interessante é a casa Zenon Rocha de 1952, na cidade de Teresina, no Piauí, projetada pelo arquiteto e cenó-
Figura 4 - Maison Errazuriz, Chile, 1930. Disponível em: <http://www. fondationlecorbusier.fr $>$. 
grafo carioca Anísio Medeiros, cuja planta parece ficar entre um "U" e um "H"; ou o conjunto de obras de Acácio Gil Borsoi, em Pernambuco e na Paraíba, ao longo da década de 1950. No caso de Borsoi, prevalecem plantas em " $L$ " e " $U$ " no lugar da divisão em dois núcleos geralmente em forma de "H", no entanto, as rampas e os meios-níveis atrelados à cobertura borboleta e a formas trapezoidais são constantes na sua obra da década 1950.
Figura 5 • Casa D'Estefani (1952) e esquema de sua implantação em série. Desenho: Marcio Cotrim. Fonte: Cotrim, 2002.
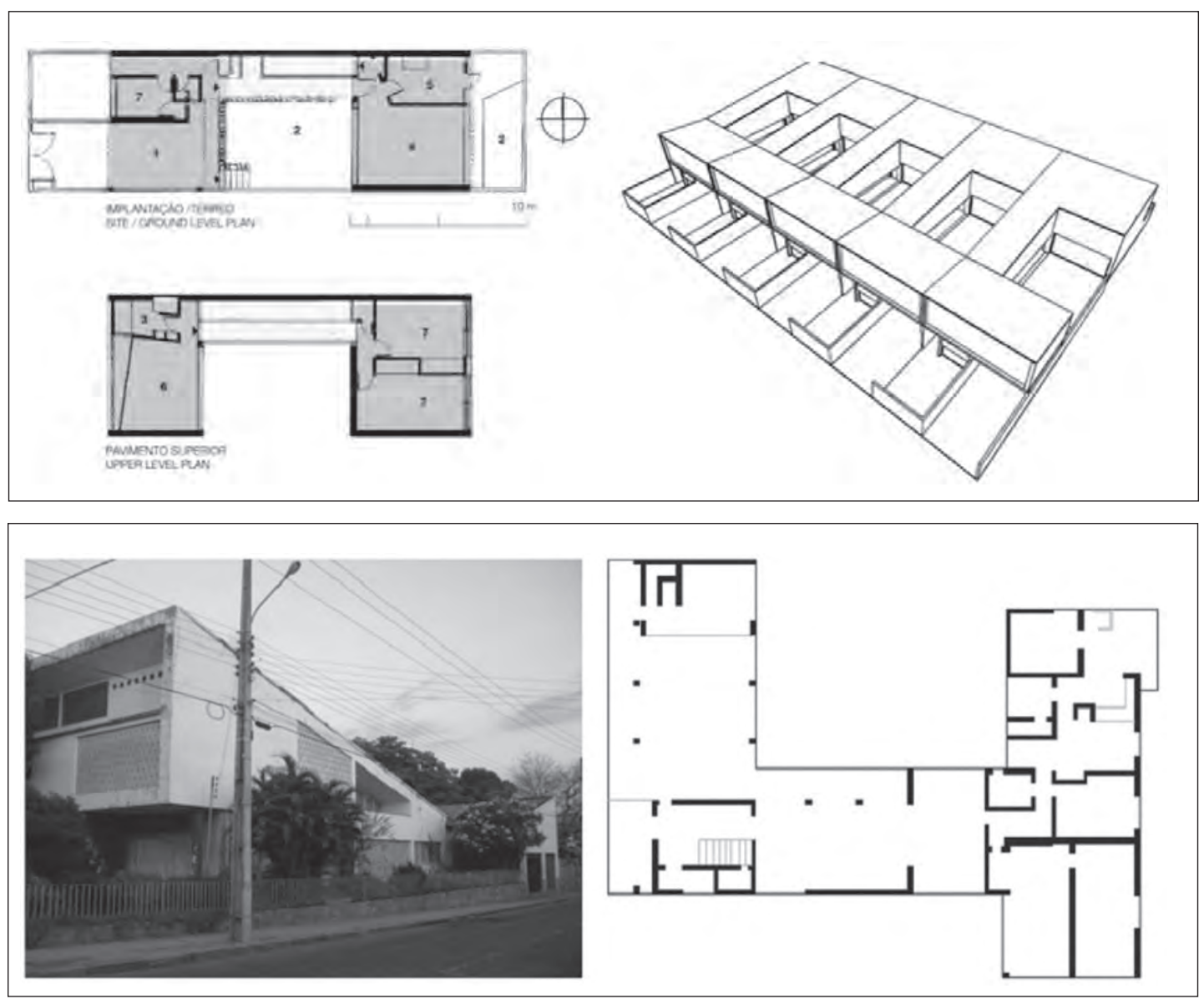

\section{A busca de um tipo na obra residencial de Mario di Lascio}

Fernando Diniz Moreira (2007) afirma que a difusão da arquitetura moderna em Salvador e Recife foi um fenômeno do segundo Pós-Guerra (apesar da obra de Luiz Nunes ou de Alexander Buddeüs) e só se concretizou com o retorno de arquitetos formados no Rio de Janeiro ou a chegada de personagens que para lá migraram. De forma similar, em João Pessoa, apesar das manifestações pioneiras de Clodoaldo Gouveia, a arquitetura moderna só se consolidou a partir de meados da década de 1950, com a chegada ou retorno de arquitetos à cidade.

Esse certamente é o caso de Mario Di Lascio, nascido em 1929, filho do arquiteto italiano Hermenegildo Di Lascio, que iniciou, na década de 1950, o curso de arquitetura na Universidade Mackenzie, em São Paulo. Porém, em virtude de problemas de saúde de
Figura 6 • Casa Zenon Rocha, 1952. Disponível em: <http://kakiafonso. blogspot.com/2009/06/casa-zenon-rochateresina-1952.html>. 
seu pai, interrompeu os estudos e retornou a João Pessoa, em 1952. Sua formação como arquiteto foi retomada posteriormente e concluída na Escola de Belas Artes de Recife, em 1957. Seus primeiros trabalhos revelam forte influência de arquitetos consagrados da arquitetura moderna brasileira, decorrente da orientação da escola de arquitetura pernambucana e principalmente de sua proximidade com Acácio Gil Borsoi (PEREIRA, 2008), que havia chegado ao Recife em 1951, após ter se formado arquiteto no Rio de Janeiro e trabalhado com Affonso Eduardo Reidy.

A produção de Mario Di Lascio é numerosa e muito diversificada. Ele atuou em repartições públicas, foi professor fundador do curso de arquitetura e urbanismo da UFPB e, paralelamente, manteve permanente atividade projetual em escritório próprio. Talvez por sua atuação estender-se por um longo período, ao lançar um olhar mais atento à sua produção, percebe-se a sua facilidade em manipular referências diversas, de fontes distintas, por vezes até contraditórias entre si (PEREIRA, 2008).

Com base na temática da casa unifamiliar, é possível fazer uma reflexão sobre questões fundamentais na obra de Mario Di Lascio, como a repetição e as particularidades de um tipo binuclear usado pelo arquiteto. É possível especular, pela leitura de casas da década de 1970, sobre uma possível fase de transição, entre uma produção moderna consagrada e a busca de novos modelos. Ao mesmo tempo, é possível constatar também que essas residências estão sendo substituídas, pela especulação imobiliária, por edifícios altos, em um processo contínuo e acelerado de verticalização, principalmente nos bairros da orla de João Pessoa.

A casa unifamiliar foi um tema frequente na trajetória profissional do arquiteto. O primeiro desses exemplares, a casa Lourenço de Miranda Freitas, de 1958, apresenta soluções que deixam transparecer a influência de sua formação moderna, como o programa setorizado em níveis interligados por rampas, o pavimento superior de volumetria trapezoidal destinado a abrigar o setor íntimo, a sala no térreo com pé-direito duplo e mezanino em meio-nível. Destoa da postura moderna a solução encontrada para a área de serviço e das dependências de empregada em bloco separado, na forma de uma "edícula" ao fundo do lote.
Figura 7 - Casa Lourenço de Miranda Freitas (1958). Fonte: Pereira (2008, p. 144-145).

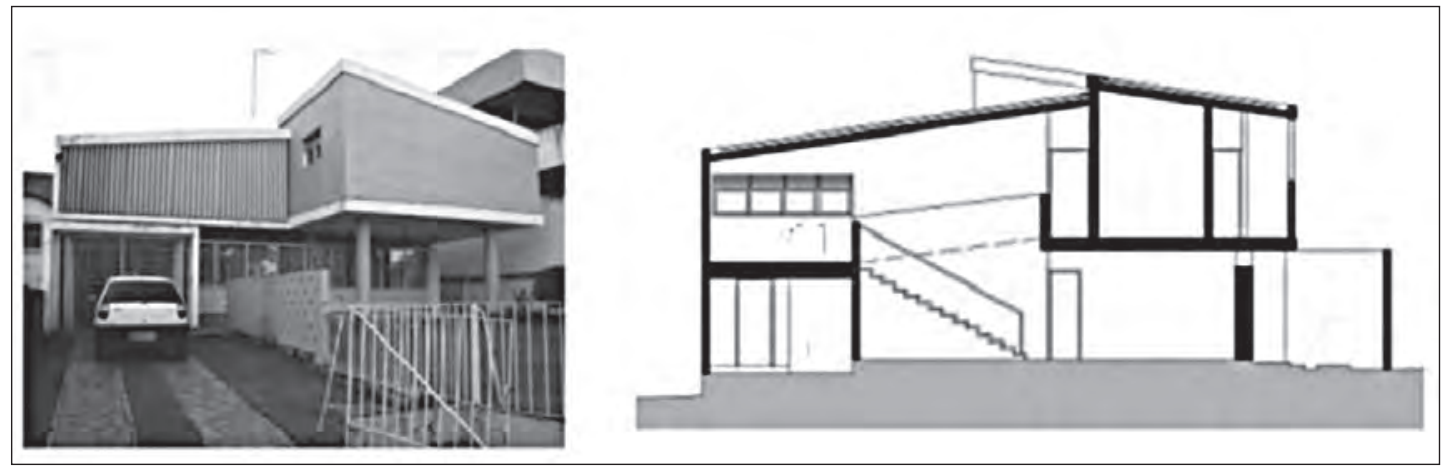

Lógica semelhante é identificável nas casas que projetou em seguida. Contudo, conforme se afasta da década de 1950, a sua obra não segue uma linha uniforme e de influências definitivas. Em outras casas posteriores, percebe-se a presença de certos elementos da arquitetura colonial, caso da residência Everaldo 
Vieira dos Santos (1969), com cobertura em quatro águas de telha canal, na qual o programa é organizado em torno de um pátio central. As áreas de convívio ficam no térreo, junto com o serviço que, nesse caso, é agregado ao corpo da edificação, e o setor íntimo é lançado no pavimento superior.

Figura 8 • Residência Everaldo Vieira dos Santos, 1969. Fonte: Pereira (2008, p. 150-151).

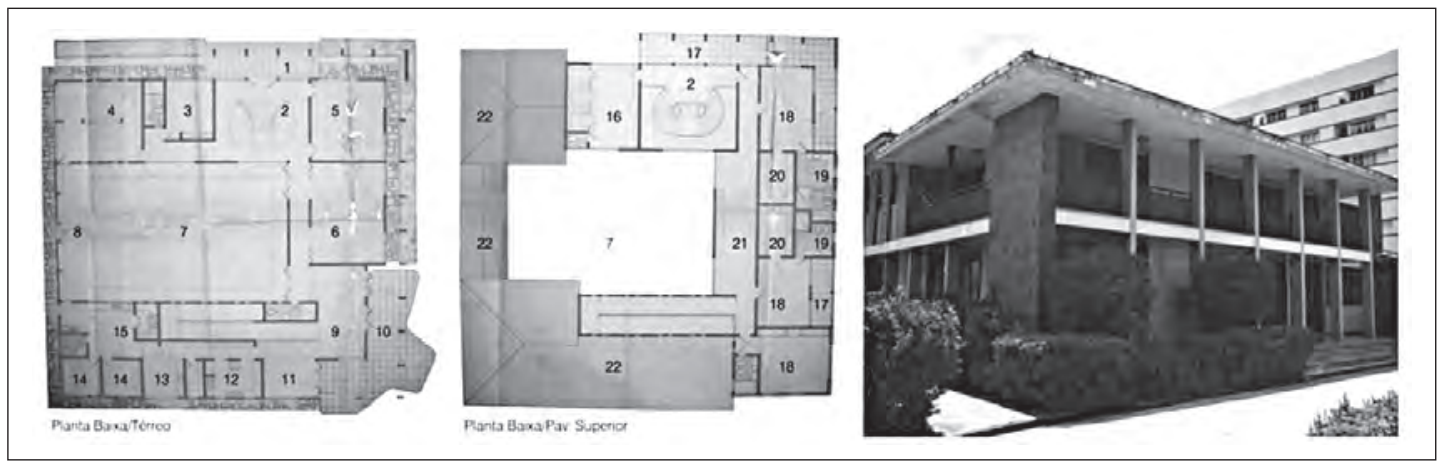

No entanto, a partir da década de 1970, em meio a um turbilhão de linguagens, é possível identificar um tipo constante de planta que parece sinalizar uma investigação própria do arquiteto sobre o programa doméstico ${ }^{6}$.

\section{Casa Francisco Xavier: a casa dentro de um jardim}

A primeira casa tratada neste ensaio foi construída para o professor universitário, Francisco Xavier, ao longo de 1975. Segundo a engenheira Maria Ângela Xavier, filha de Francisco Xavier, seu pai pediu a Mario Di Lascio que fizesse "uma casa dentro de um jardim."

A casa ocupa um terreno de esquina de $25 \times 30 \mathrm{~m}$, no bairro do Cabo Branco (Av. Antônio Lira e Av. Adolfo Loureiro França), zona residencial da orla de João Pessoa e atualmente um dos metros quadrados mais caros da cidade, fato que tem levado construtores e agentes imobiliários a pressionarem os proprietários da região a venderem suas casas, dando lugar a edifícios residenciais e flats em altura. Dentro desse contexto, é curioso o fato de a casa Francisco Xavier manter-se inalterada e nas mãos da mesma família, considerando a excelente orientação e as dimensões generosas do terreno, quando comparado com outros da mesma quadra.

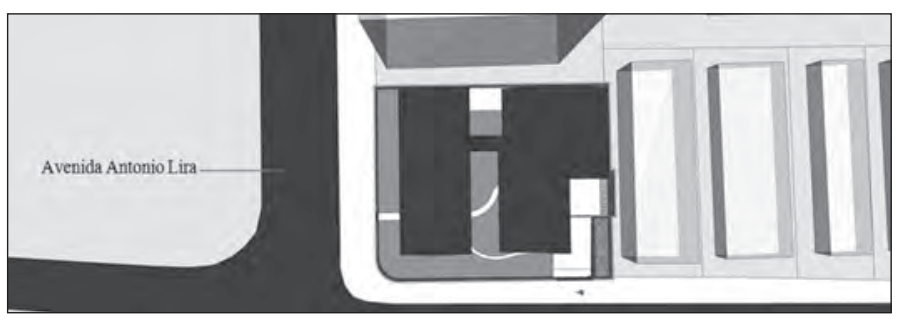

Mario Di Lascio ocupa o lote, chegando aos limites permitidos pelos recuos. No entanto, "areja" essa ocupação por meio de duas operações decisivas: (1) a separação do programa em dois corpos em níveis intermediários (destinados a atividades diurnas

7. Depoimento cedido a Raissa Cunha Rodrigues e Lívia Sarmento, em entrevista realizada no segundo semestre de 2011, como atividade da pesquisa $\mathrm{HM}+\mathrm{HC}$ Habitar Moderno+Habitar Contemporâneo, vinculada ao LPPM-PPGAU-UFPB

Figura 9 - Casa Francisco Xavier (1975) Fonte: desenho elaborado por Raissa Cunha Rodrigues e Lívia Sarmento como atividade da pesquisa $\mathrm{HM}+\mathrm{HC}$ Habitar Moderno+Habitar Contemporâneo, vinculada ao LPPM-PPGAU-UFPB. 
e noturnas) interligados por uma rampa; (2) a liberação do solo por meio de pilotis sob o volume destinado às atividades predominantemente noturnas.

Essas duas operações ainda parecem resolver os problemas ligados aos acessos e à orientação solar adequada para João Pessoa. Os dois corpos citados anteriormente são dispostos em paralelo à Av. Antonio Lira. Dessa forma, no bloco destinado aos quartos, esses são abertos para o leste, enquanto a circulação e banheiros localizam-se a oeste, ao lado do pátio. Enquanto no bloco destinado às atividades comuns e aos serviços, as salas de estar e jantar e o escritório estão localizados a leste, ao lado do pátio, os serviços e a garagem estão a oeste. Essa decisão determina a maior face aberta de cada bloco, voltada ao quadrante dos ventos predominantes, enquanto o pátio interno, gerado entre os dois blocos, aberto a norte, permite a ventilação cruzada.

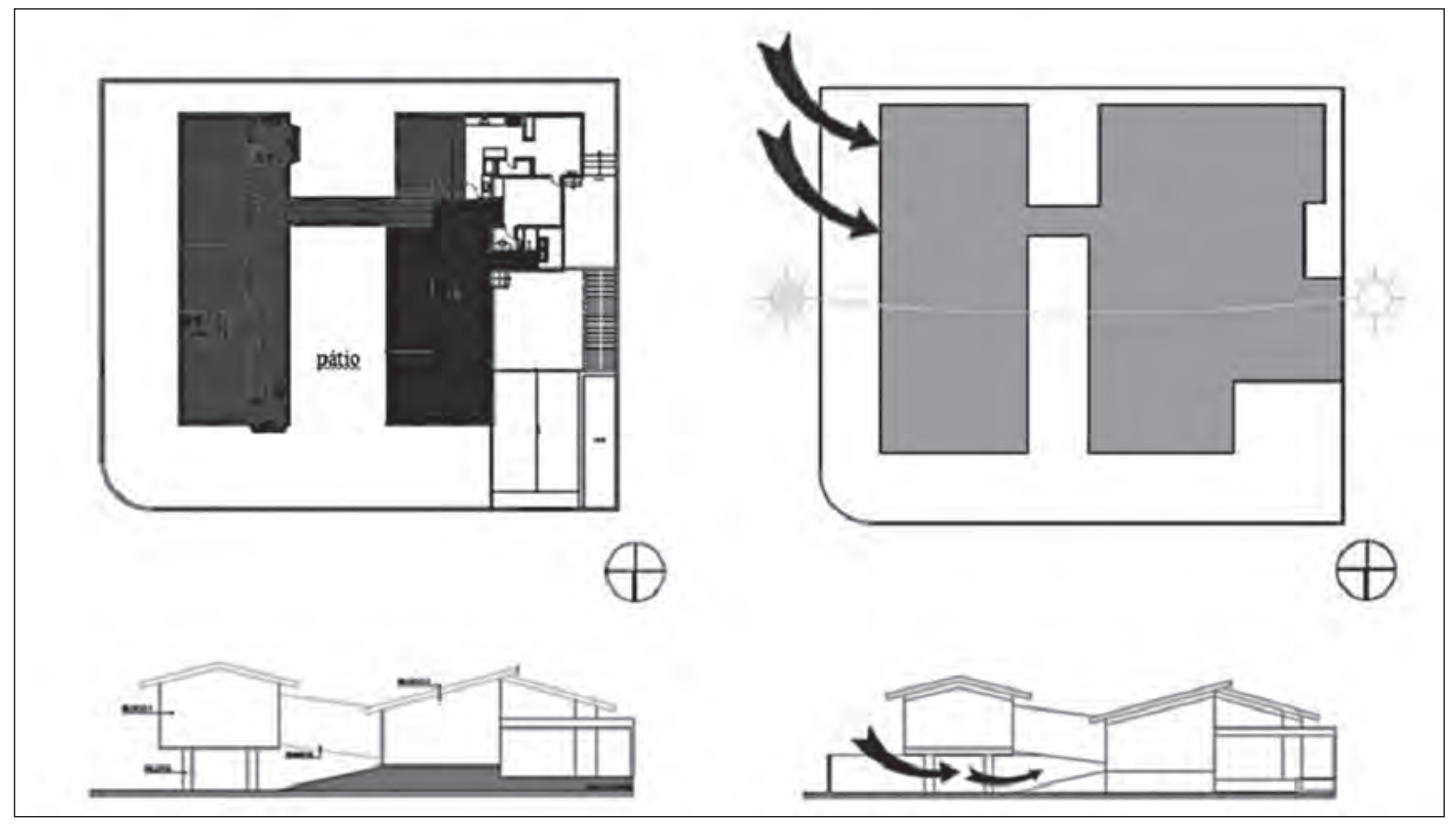

Essa lógica, somada à liberação do terreno sob o bloco dos dormitórios, induz, ao que tudo indica, à separação dos acessos de pedestres e de automóveis. Automóveis acessam a casa pela Av. Adolfo Loureiro, conectando seu condutor diretamente aos serviços e à cozinha, na orientação menos favorável, enquanto o acesso ao pedestre é feito pela outra avenida, de forma bem mais pitoresca, por meio de um caminho ligeiramente curvo sob o bloco dos quartos, área tomada pela vegetação que serpenteia entre os pilotis, cruzando o pátio que leva o visitante até um terraço que faz as vezes de hall. É provável que seja nessa travessia onde Mario Di Lascio tenha alcançado, de forma mais contundente, o desejo do seu cliente, "uma casa dentro de um jardim".

Volumetricamente a casa corresponde ao exposto até aqui. No entanto, no que diz respeito aos materiais e linguagem de maneira geral, a proposta é bem menos radical e concilia uma imagem mais tradicional de telhas de cerâmica em duas águas com outra mais contemporânea, que expõe alguns elementos estruturais ou ainda uma fachada composta de diferentes materiais.
Figura 10 • Casa Francisco Xavier (1975) Fonte: desenho elaborado por Raissa Cunha Rodrigues e Lívia Sarmento como atividade da pesquisa $\mathrm{HM}+\mathrm{HC}$ Habitar Moderno+Habitar Contemporâneo, vinculada ao LPPM-PPGAU-UFPB. 


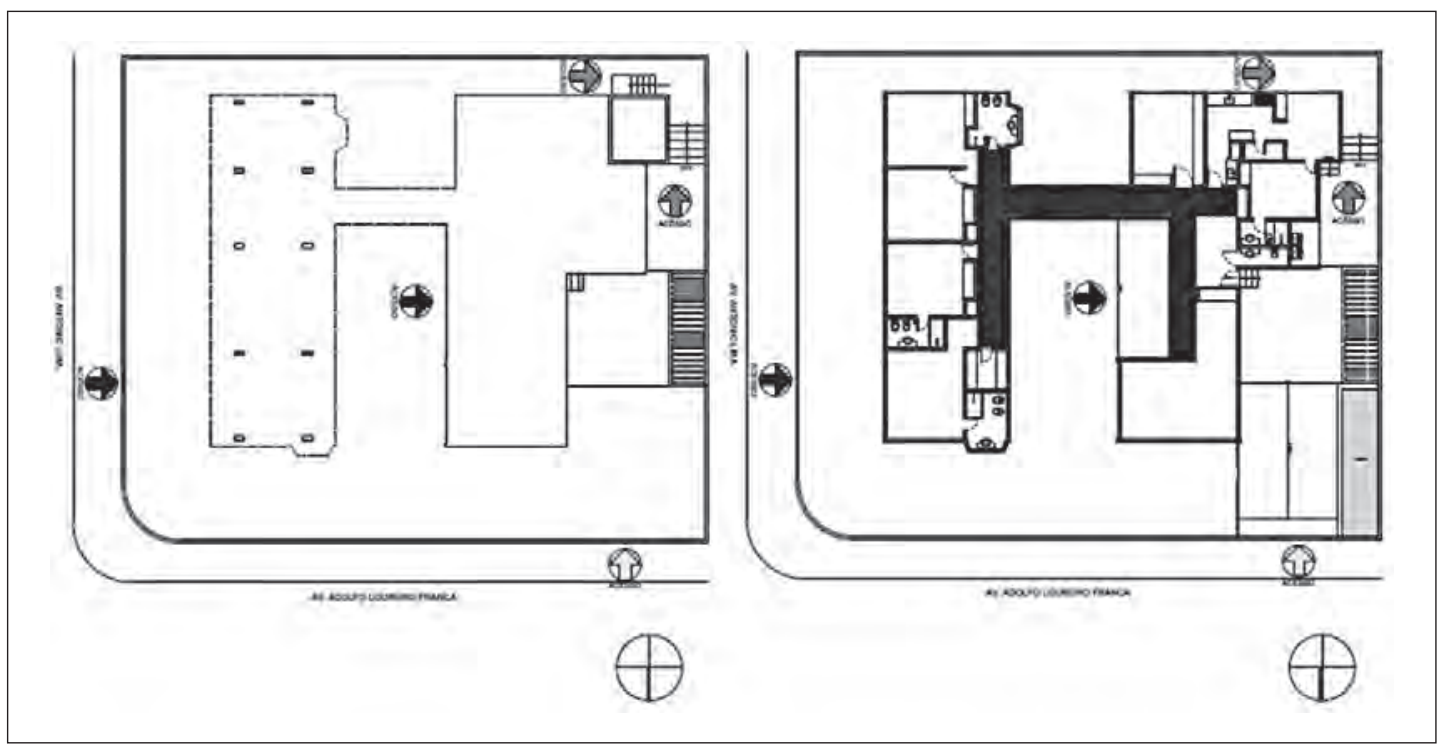

Figura 11 - Casa Francisco Xavier (1975). Fonte: desenho elaborado por Raissa Cunha Rodrigues e Lívia Sarmento como atividade da pesquisa $\mathrm{HM}+\mathrm{HC}$ Habitar Moderno+Habitar Contemporâneo, vinculada ao LPPM-PPGAU-UFPB.

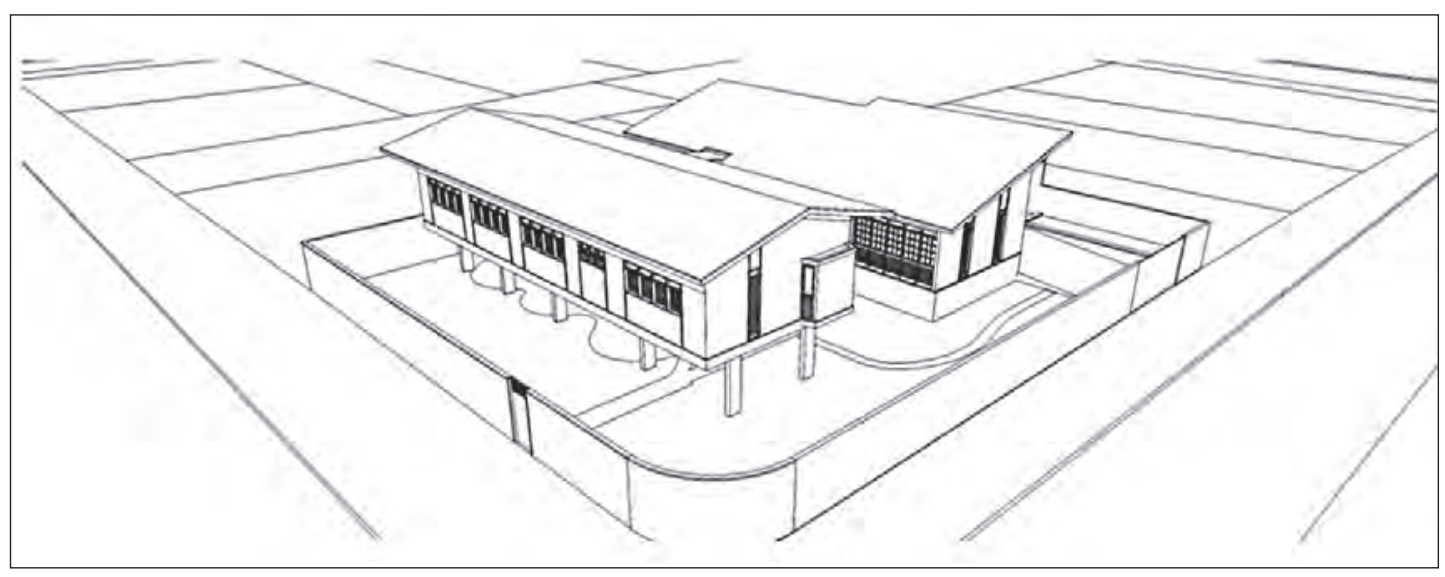

\section{Casa Múcio Souto}

A casa construída entre 1978 e 1979 para Múcio Antonio Sobreira Souto foi, em 2011, demolida, dando lugar a um novo edifício, fato que indica a velocidade com que a cidade vem sendo transformada e a efemeridade dos projetos. A casa Múcio Souto ocupava a primeira linha de construções em frente ao mar, na Avenida Cabo Branco, no bairro homônimo. Local onde, por razões óbvias, prevalecem terrenos com a menor face voltada para o mar.

O terreno ocupa no seu sentido longitudinal toda a extensão da quadra, possibilitando acesso tanto pela face leste (mar) como pela face oeste (barreira). ${ }^{8}$ Mario Di Lascio optou por dividir o programa da casa em três volumes dispostos longitudinal-
Figura 12 - Casa Francisco Xavier (1975). Fonte: modelo elaborado por Raissa Cunha Rodrigues e Lívia Sarmento como atividade da pesquisa $\mathrm{HM}+\mathrm{HC}$ Habitar Moderno+Habitar Contemporâneo, vinculada ao LPPMPPGAU-UFPB.

8. Barreira é como ficou conhecido uma parcela de mata atlântica preservada dentro da cidade, separando dois bairros da cidade, Cabo Branco e o Altiplano Cabo Branco.

Cadernos de Arquitetura e Urbanismo, v.18, n.22, 21 sem. 2011 
mente ao longo do terreno e mais próximos de uma das laterais (norte) liberando a outra lateral para o acesso por ambos os lados (leste e oeste). Cada um dos volumes atende a uma parte determinada das atividades. Da Barreira em direção ao mar, temos: o primeiro volume, em $L$, destinado à garagem, lavanderia, depósito e dois dormitórios de serviço; o volume do meio, onde se concentram as áreas coletivas da casa, estar, jantar, terraços e cozinha, além de sauna e escritório; e, por último, elevado sobre pilotis e conectado por uma rampa com o volume descrito anteriormente, as três suítes com varandas e vistas ao mar.

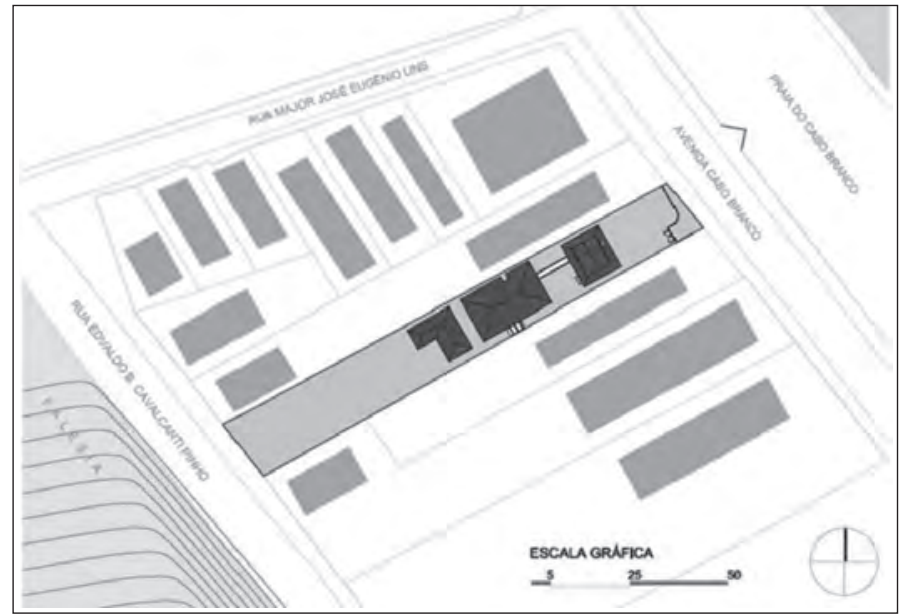

Figura 13 • Casa Múcio Souto (19781979). Fonte: desenho elaborado por Fillipe Albuquerque Miranda e Davi Pereira Lucena como atividade da pesquisa $\mathrm{HM}+\mathrm{HC}$ Habitar Moderno+Habitar Contemporâneo, vinculada ao LPPM-PPGAU-UFPB.

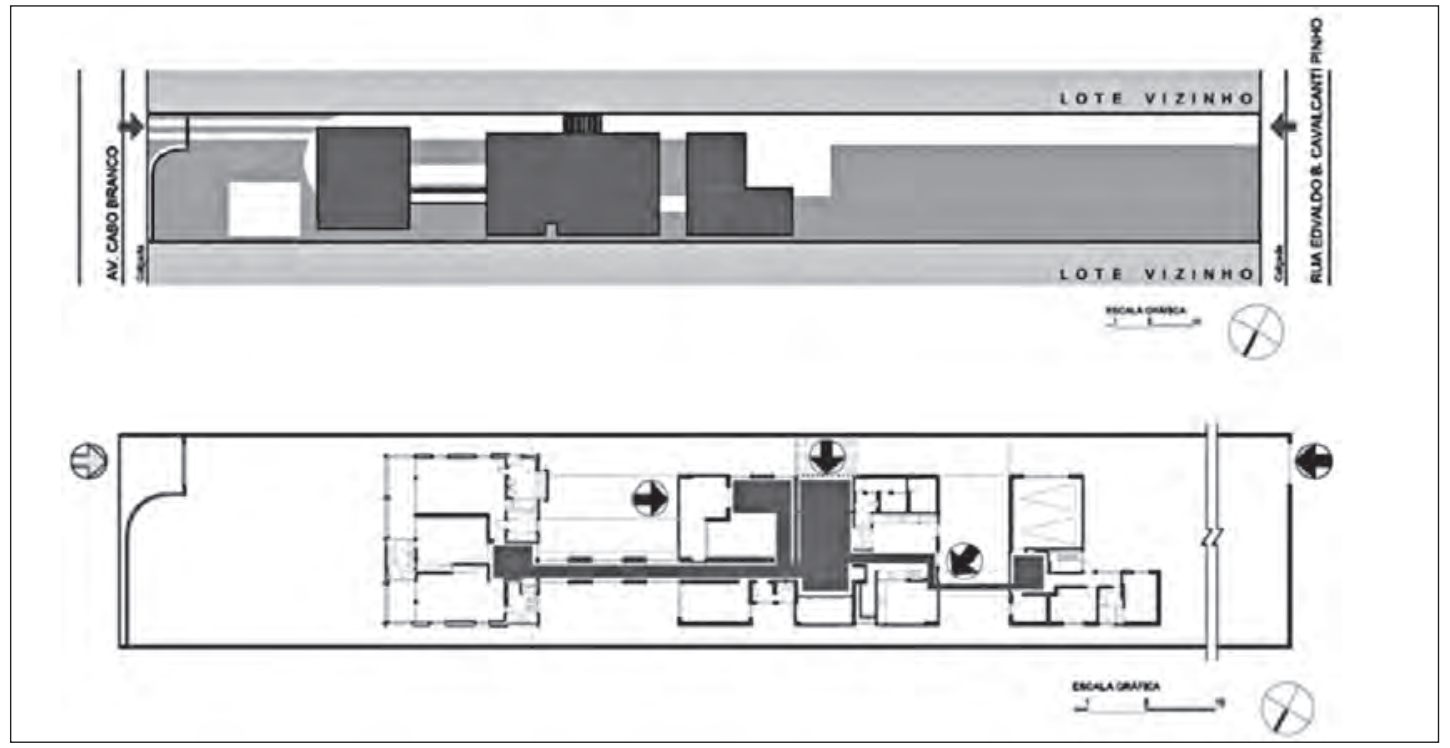

Ao deixarmos de lado o corpo isolado da garagem e serviços, a descrição da casa assemelha-se à feita anteriormente sobre a casa Francisco Xavier. Dois corpos interligados por rampas em níveis intermediários. Um com as zonas coletivas, o outro com as zonas íntimas elevado sobre pilotis, os quais definem uma zona aberta e sombreada destinada ao ócio e lazer. Entretanto, enquanto a casa Francisco Xavier mantém uma clara unidade do ponto de vista da linguagem externa, a casa Múcio Souto caracteriza-se por uma
Figura 14 • Casa Múcio Souto (19781979). Fonte: desenho elaborado por Fillipe Albuquerque Miranda e Davi Pereira Lucena como atividade da pesquisa $\mathrm{HM}+\mathrm{HC}$ Habitar Moderno+Habitar Contemporâneo, vinculada ao LPPM-PPGAU-UFPB.

Cadernos de Arquitetura e Urbanismo, v.18, n.22, $1^{0}$ sem. 2011 
atitude insólita, em que cada um dos volumes que configuram o sistema binuclear descrito é tratado de forma particular. O corpo central, destinados às atividades predominantemente diurnas, é marcado por características híbridas, prevalecendo uma linguagem mais tradicional: cobertura cerâmica em quatro águas, tijolos à vista e cheios prevalecendo sobre vazios. O volume mais próximo ao mar assume o papel de fachada, escondendo literalmente as outras. Nesse caso, prevalece, ao menos como imagem, a semelhança com a arquitetura em concreto armado aparente, tão em voga nas décadas de 1960 e 1970 por todo o Brasil, na qual à estrutura é atribuída toda a expressividade do projeto.

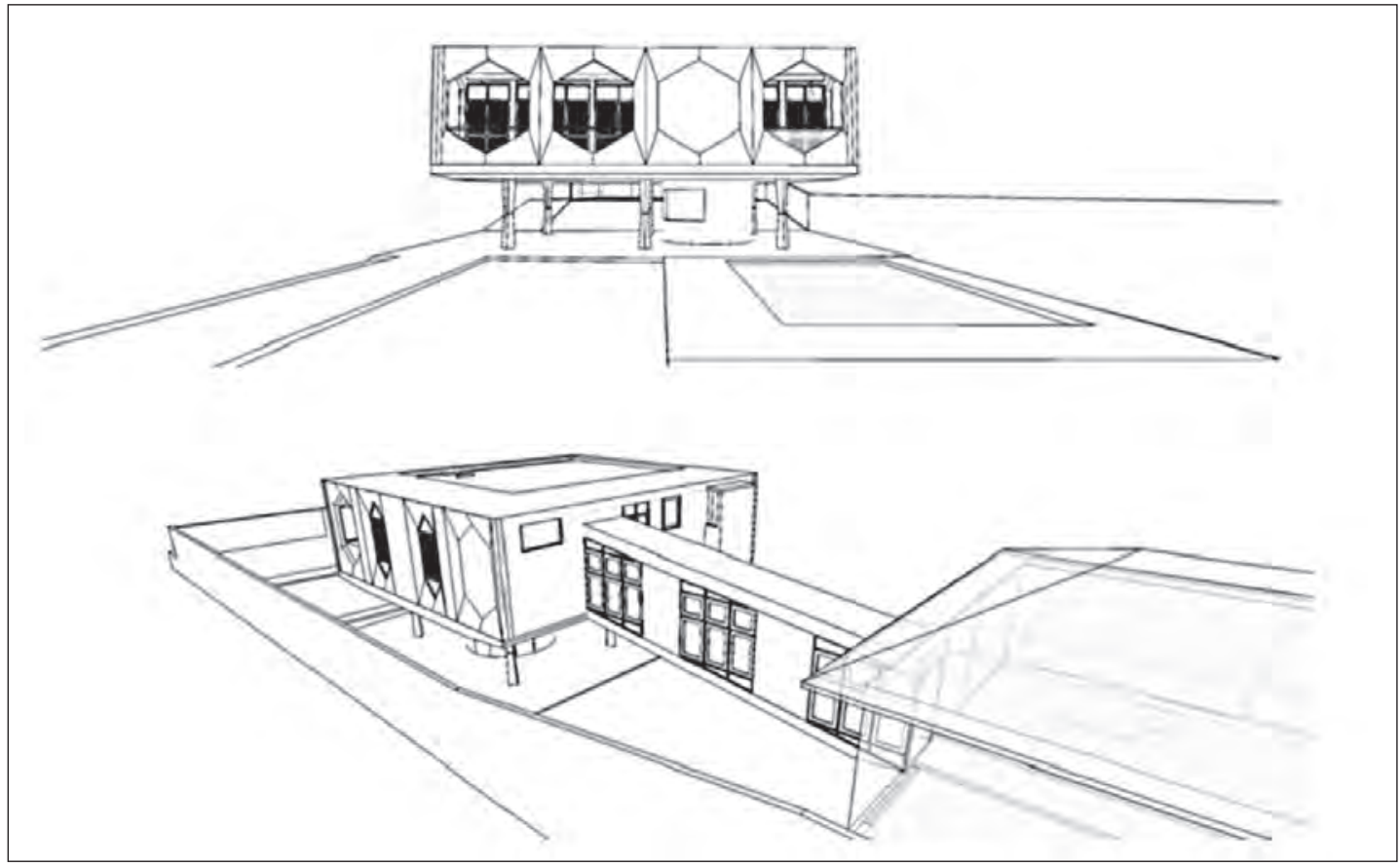

Tal relação é ainda mais evidente quando, em uma leitura detaIhada, relaciona-se quase literalmente o pilar triangular usado por Mario Di Lascio com os pilares da Faculdade de Arquitetura e Urbanismo da Universidade de São Paulo, projeto paradigmático de Vilanova Artigas e Carlos Cascaldi, da década de 1960.

A imagem evocada é a de uma importante viga vierendel que delimita as varandas das suítes e filtra, por meio de aberturas hexagonais, o sol da manhã. O resultado induz, inevitavelmente, a pensar na casa em Brasília projetado por João Filgueiras Lima, Lelé, em meados da década de 1960. Entretanto, à diferença de Lelé, Mario Di Lascio constrói uma "falsa viga" nas faces em balanço, que parece servir à intenção inicial do arquiteto de propor uma fachada que representasse o espírito da época.

A falta de unidade entre os dois primeiros corpos da casa Múcio Souto é evidenciada quando comparada, por meio das proporções e alinhamentos, à implantação da casa Francisco Xavier, cuja unidade se revela como um quadrado do qual se extrai a fatia central. Na casa Múcio Souto, inexiste relações geométricas em planta entre os volumes, com exceção dos alinhamentos laterais oriundos da legislação relativa aos recuos.
Figura 15 • Casa Múcio Souto (19781979). Fonte: desenho elaborado por Fillipe Albuquerque Miranda e Davi Pereira Lucena como atividade da pesquisa $\mathrm{HM}+\mathrm{HC}$ Habitar Moderno+Habitar Contemporâneo, vinculada ao LPPM-PPGAU-UFPB. 

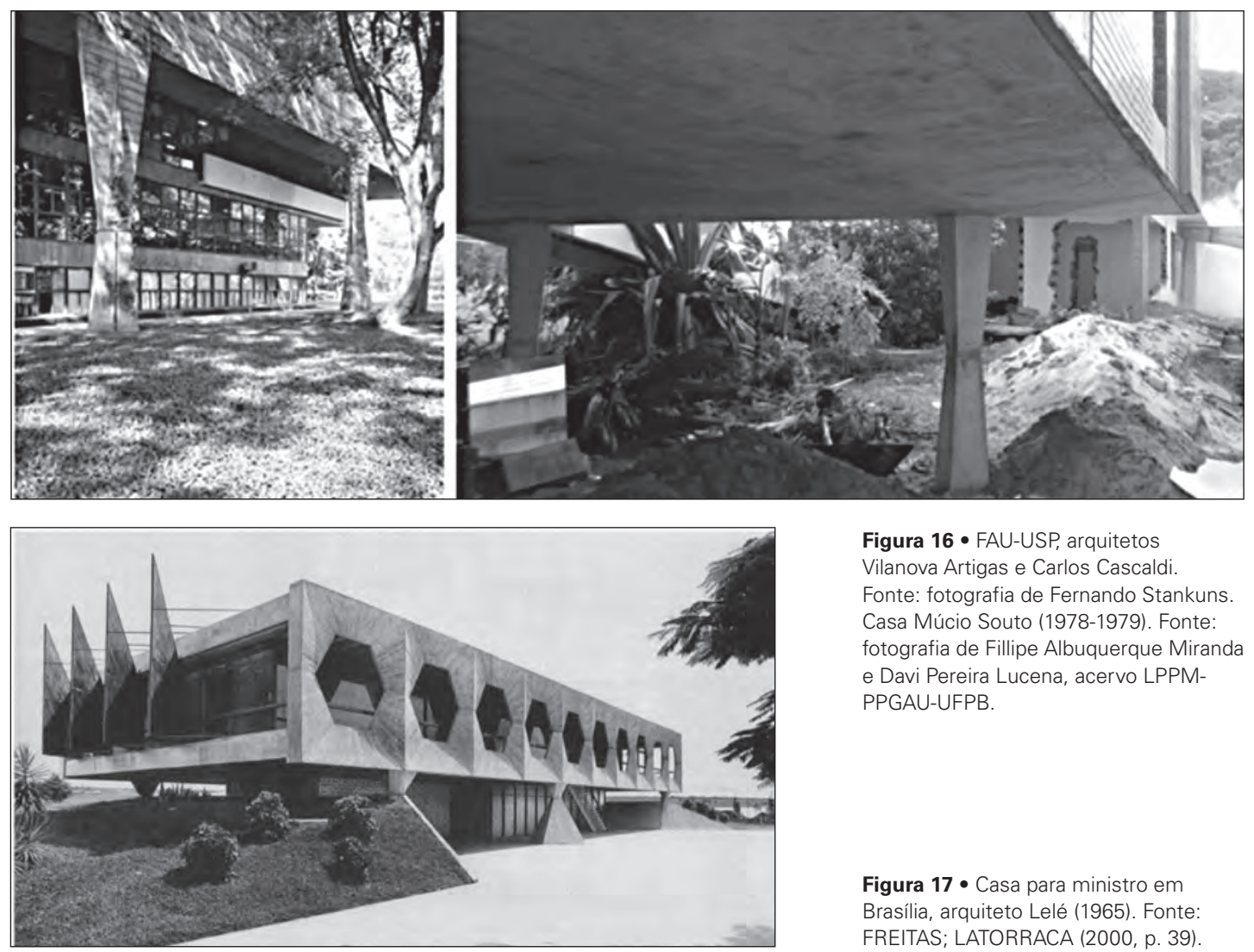

Figura $16 \cdot$ FAU-USP, arquitetos

Vilanova Artigas e Carlos Cascaldi.

Fonte: fotografia de Fernando Stankuns. Casa Múcio Souto (1978-1979). Fonte: fotografia de Fillipe Albuquerque Miranda e Davi Pereira Lucena, acervo LPPMPPGAU-UFPB.

Figura 17 - Casa para ministro em Brasília, arquiteto Lelé (1965). Fonte: FREITAS; LATORRACA (2000, p. 39).
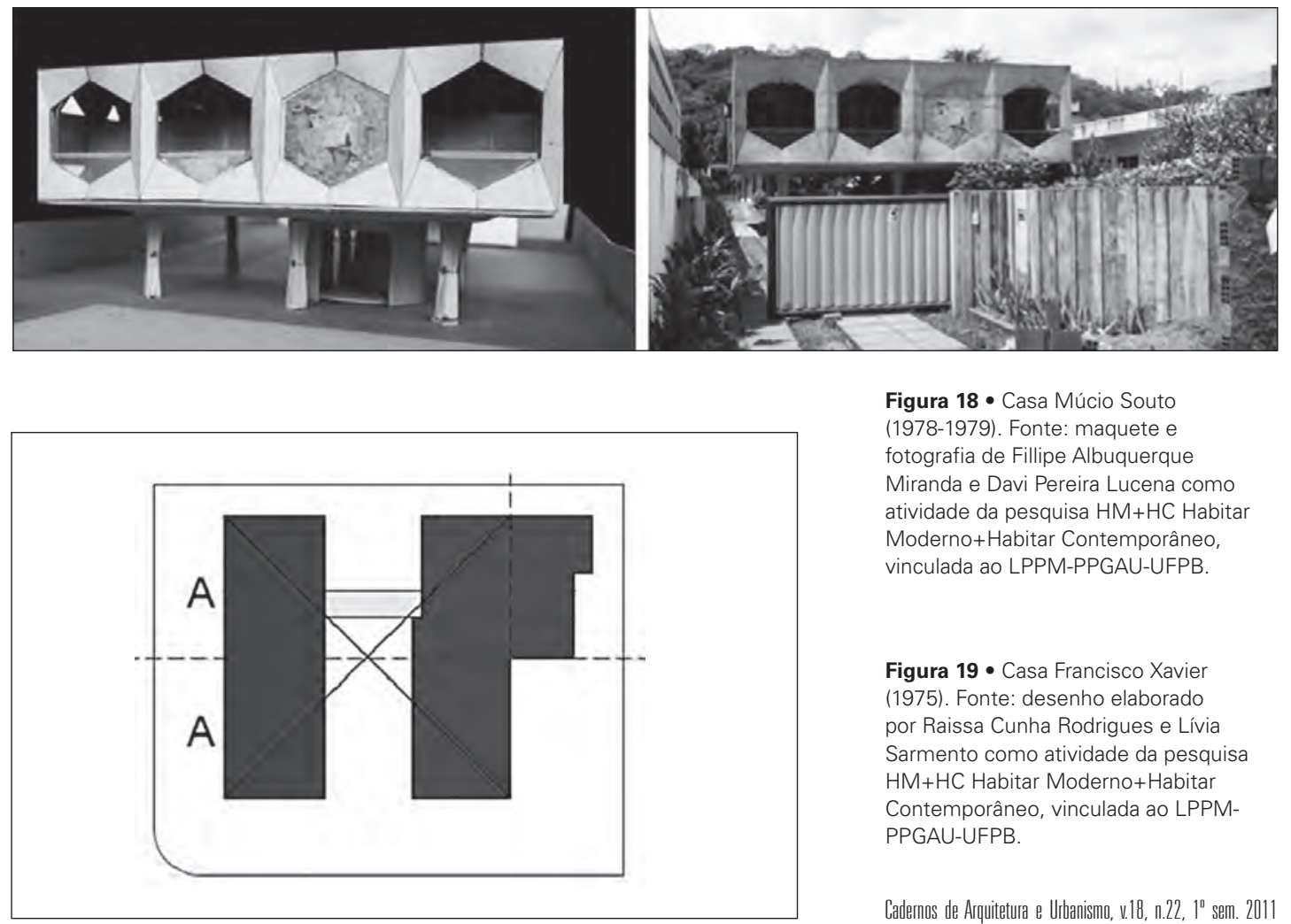

Figura 18 • Casa Múcio Souto (1978-1979). Fonte: maquete e fotografia de Fillipe Albuquerque Miranda e Davi Pereira Lucena como atividade da pesquisa $\mathrm{HM}+\mathrm{HC}$ Habitar Moderno+Habitar Contemporâneo, vinculada ao LPPM-PPGAU-UFPB.

Figura 19 - Casa Francisco Xavier (1975). Fonte: desenho elaborado por Raissa Cunha Rodrigues e Lívia Sarmento como atividade da pesquisa $\mathrm{HM}+\mathrm{HC}$ Habitar Moderno+Habitar Contemporâneo, vinculada ao LPPMPPGAU-UFPB.

Cadernos de Arquitetura e Urbanismo, v.18, n.22, $1^{0}$ sem. 2011 


\section{Enfim}

O uso de esquemas binucleares por Mario Di Lascio para enfrentar o programa doméstico não ocorreu isoladamente nas duas casas anteriormente comentadas. Como dito anteriormente, embora, na década de 1970, a obra de Mario Di Lascio fosse marcada por um turbilhão de propostas diferentes, ora mais próximas da tal "herança carioca", via Acácio Gil Borsoi, ora mais atualizada com as arquiteturas em concreto armado em estado bruto, dos paulistas, ora mais digeríveis para o cidadão comum, por meio de experimentos "neocoloniosos", há uma investigação sobre a casa dividida em dois núcleos que percorre diversos períodos e diversos projetos. Provavelmente o primeiro projeto tenha sido a casa José Farias Neves, de 1973, em que o arquiteto adotou uma solução de planta binuclear em " $\mathrm{H}$ ": um bloco frontal abrigando o convívio no térreo e o setor íntimo no pavimento superior, seguido do volume estreito da rampa que interliga, em meio-nível, o primeiro bloco ao setor de refeições, cozinha e serviço. Nessa casa, a opção por rampas em meios-níveis decorre da forte topografia do terreno, tornando-se uma solução eficiente na organização do programa. No entanto, nas outras duas casas vistas anteriormente (Francisco Xavier e Múcio Souto), essa opção é tomada pelo arquiteto sem nenhuma justificativa topográfica, forçando-o, inclusive, a criar uma plataforma para gerar as diferenças de níveis e assim ordenar o programa em meios-níveis. Há, portanto, uma clara imposição tipológica que se assemelha à levada ao cabo, na década de 1960, por Vilanova Artigas.
Figura 20 - Residência José Farias Neves, 1973. Fonte: Arquivo Central PMJP (apud PEREIRA, 2008, p. 152).

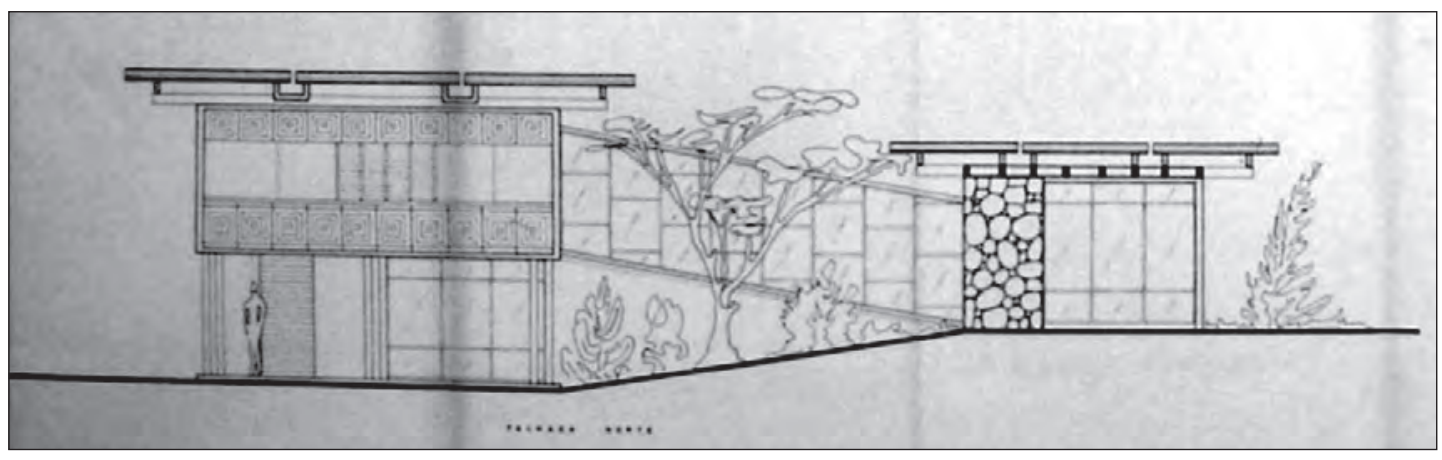

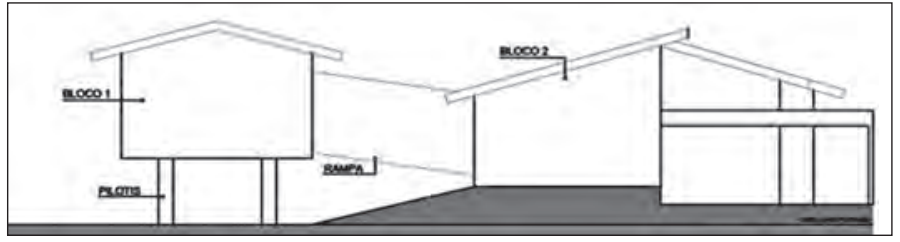

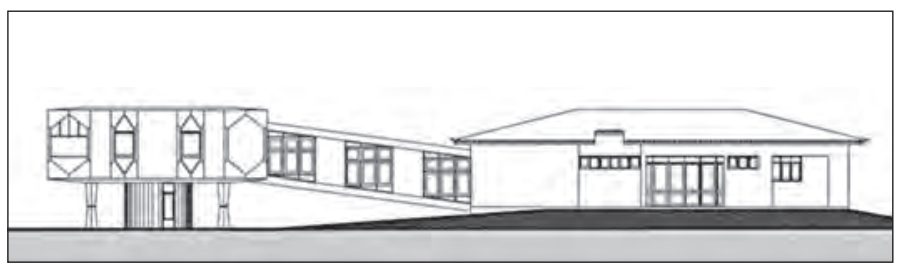

Figura 21 - Casa Francisco Xavier (1975). Fonte: desenho elaborado por Raissa Cunha Rodrigues e Lívia Sarmento como atividade da pesquisa $\mathrm{HM}+\mathrm{HC}$ Habitar Moderno+Habitar Contemporâneo, vinculada ao LPPMPPGAU-UFPB.

Figura 22 • Casa Múcio Souto (19781979). Fonte: desenho elaborado por Fillipe Albuquerque Miranda e Davi Pereira Lucena como atividade da pesquisa $\mathrm{HM}+\mathrm{HC}$ Habitar Moderno+Habitar Contemporâneo, vinculada ao LPPM-PPGAU-UFPB. $\mathrm{HM}+\mathrm{HC}$ Habitar Moderno+Habitar Contemporâneo, vinculada ao LPPMPPGAU-UFPB.

Cadernos de Arquitetura e Urbanismo, v.18, n.22, 21 $11^{\circ}$ sem. 2011 

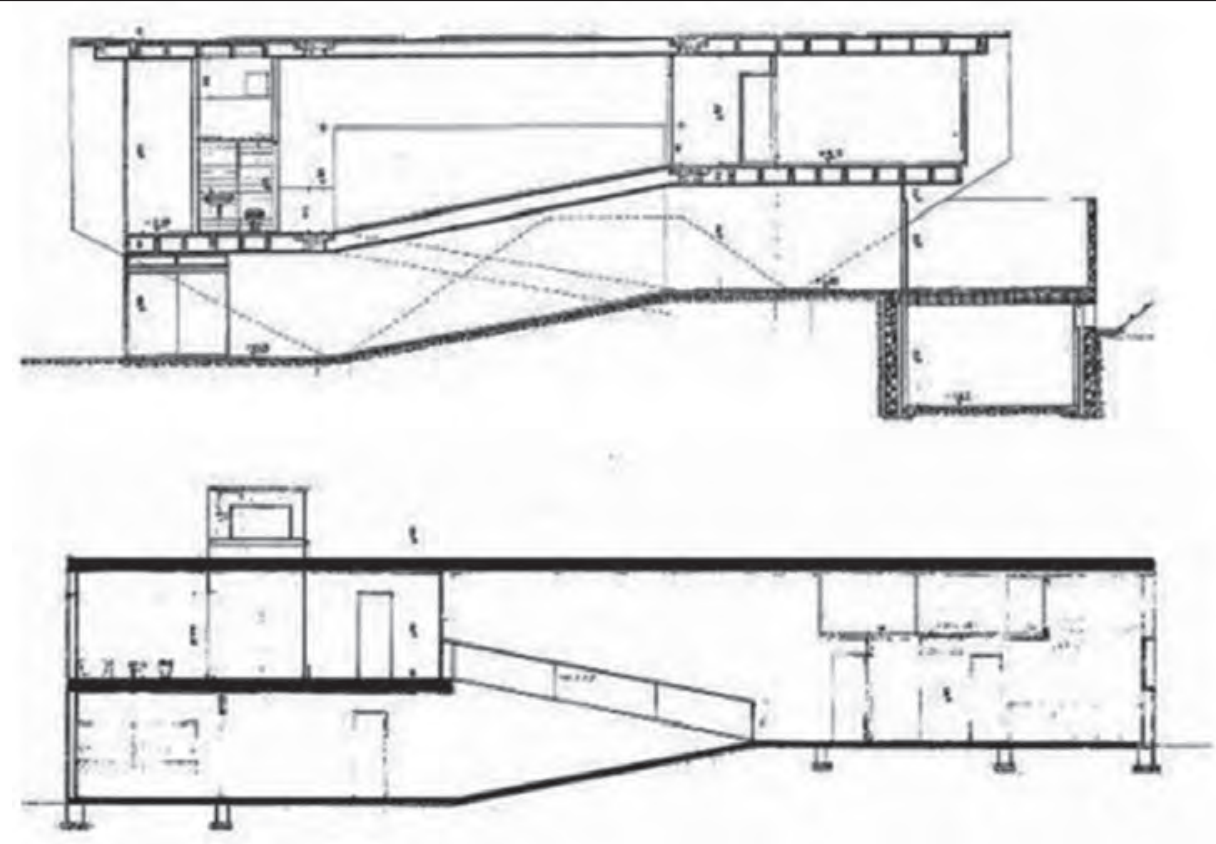

Nesses casos, e agora incluindo também a casa José Farias Neves, há certo desinteresse pelo pátio (resíduo) gerado pelo comprimento exigido pela rampa entre os dois núcleos, numa atitude que se distancia radicalmente da resultante das plantas em " $\mathrm{H}$ " de Marcel Breuer para os Estados Unidos ou nas versões de Oswaldo Bratke para São Paulo. Provavelmente seja consequência da priorização da área sob pilotis (sombreada e mais adequada ao clima), enquanto os pátios serviam mais como recurso de ventilação do que local de permanência. Tal operação parece derivar mais do apreendido de Acácio Gil Borsoi em casas como a de Renato Ribeiro Coutinho ou Pompeu Maroja, realizadas em João Pessoa, na década de 1950.

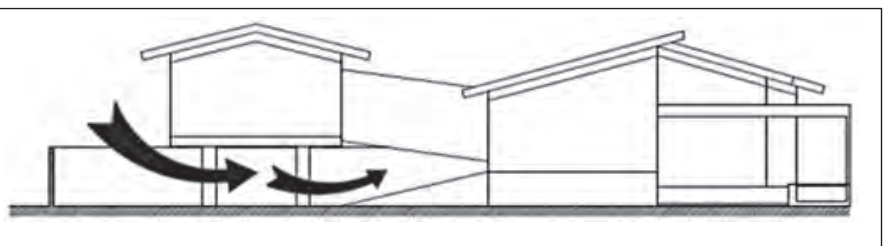

O que de fato parece ficar claro é que, por trás da experimentação constante de um tipo de planta (no caso a "H" em meios-níveis articulados por rampas), há uma enorme facilidade em manipular referências diversas em um mesmo projeto. Marcel Breuer, Oswaldo Bratke, Vilanova Artigas, Oscar Niemeyer, Acácio Gil Borsoi, entre outros, ecoam constantemente nesses projetos. Manipulação de citações diversas e contraditórias que define uma atitude antecipatória da década de 1980. Não é de se estranhar que a casa Múcio Souto seja uma das últimas da década de 1970. A década termina, simbolicamente, com uma imagem que prenuncia novos tempos, com um simulacro de viga. De fato, a década de 1980 tinha começado.
Figura 23 - Cortes da segunda casa Mario Taque Bittencourt (1959) e da casa Hanns Victor Troastli (1958), arquiteto Vilanova Artigas. Fonte: Cotrim (2008, p. 136).

Figura 24 - Casa Francisco Xavier (1975). Fonte: desenho elaborado por Raissa Cunha Rodrigues e Lívia Sarmento como atividade da pesquisa $\mathrm{HM}+\mathrm{HC}$ Habitar Moderno+Habitar Contemporâneo, vinculada ao LPPMPPGAU-UFPB.

Cadernos de Arquitetura e Urbanismo, v.18, n.22, $1^{0}$ sem. 2011 


\section{Referências}

ARAÚJO, Ricardo Ferreira de; TINEM, Nelci; COTRIM, Marcio. Arquitetura residencial moderna em João Pessoa nos anos de 1970. Arquitextos, São Paulo, n. 126.03, a. 11, nov. 2010. Disponível em: <http://www.vitruvius.com.br/revistas/read/arquitextos/11.126/3651>. Acessado em: 01.03.2012.

BREUER, Marcel. Casas americanas. Revista 2G, Barcelona, n. $17,2001$.

COBBERS, Arnt. Marcel Breuer: 1902-1981. Köln: Taschen, 2009.

COTRIM, Marcio. Construir a casa paulista: o discurso e a obra de Artigas entre 1967-1985. 2008. 575 f. Tese (Doutorado em Teoria e história da arquitetura e da cidade) - ETSAB-UPC, Barcelona.

COTRIM, Marcio. Diálogos imaginários: Marcel Breuer e Villanova Artigas. Arquitextos, São Paulo, n. 064.08, a. 6, set. 2005. Disponível em: <http://www.vitruvius.com.br/revistas/read/arquitextos/06.064/428>. Acessado em: 28.02.2012.

COTRIM, Marcio. João Batista Vilanova Artigas: doze casas paulistas, 1942 a 1969. 2002. 130 f. Dissertação (Mestrado em Teoria e história da arquitetura e da cidade) - ETSAB-UPC, Barcelona.

FREITAS, Esequias Souza de; LATORRACA, Giancarlo. João Filgueiras Lima, Lelé. Lisboa: Editorial Blau, 2000.

MOREIRA, Fernando Diniz. Arquitetura moderna no Norte e Nordeste do Brasil: universalidade e diversidade. Recife: CECI/ Unicap, 2007.

PEREIRA, Fúlvio Teixeira de Barros. Difusão da arquitetura moderna na cidade de João Pessoa (1956-1974). 2008. 276 f. Dissertação (Mestrado em Arquitetura e Urbanismo) - PPGAU, Escola de Engenharia de São Carlos, Universidade de São Paulo, São Carlos.

SEGAWA, Hugo; DOURADO, Guilherme Mazza. Oswaldo Arthur Bratke. São Paulo: Proeditores, 1997.

\section{Endereço dos autores}

Marcio Cotrim

Rua Maria Elizabeth, 87/105

58045-230 - João Pessoa-PB

E-mail:marcio@vitruvius.es

Nelci Tinem

Rua Tabelião José Ramalho Leite 1531/101

58045-230 - João Pessoa-PB

E-mail: ntinem@uol.com.br

Wylnna C. L. Vidal

Rua Pedro Juscelino de Aquino, 231

Jardim Cidade Universitária

58052-370 - João Pessoa-PB

E-mail:wylnna@yahoo.com.br 